\title{
Morphological Features and Biomass Partitioning of Lucerne Plants (Medicago sativa L.) Subjected to Water Stress
}

\author{
Yong-Zhong Luo ${ }^{1}$, Guang Li ${ }^{1, *}$, Guijun Yan ${ }^{2}$ (D), Hui Liu ${ }^{2}$ and Neil C. Turner ${ }^{2, *(1)}$ \\ 1 College of Forestry, Gansu Agricultural University, Lanzhou 730070, China; luoyzhong@gsau.edu.cn \\ 2 UWA School of Agriculture and Environment and UWA Institute of Agriculture, The University of Western \\ Australia, Locked Bag 5005, Perth, WA 6001, Australia; guijun.yan@uwa.edu.au (G.Y.); \\ hui.liu@uwa.edu.au (H.L.) \\ * Correspondence: lig@gsau.edu.cn (G.L.); neil.turner@uwa.edu.au (N.C.T.); Tel.: +86-13893272883 (G.L.); \\ +061-418286487 (N.C.T.)
}

Received: 3 February 2020; Accepted: 22 February 2020; Published: 27 February 2020

\begin{abstract}
Drought is one of the major abiotic stresses affecting the morphological, physiological, and metabolic processes of plants, and hence their growth and production on a global scale. Lucerne (Medicago sativa L.) is one of the most popular pasture species in semi-arid regions and plays a critical role in sustaining agricultural systems in many areas of the world. In order to evaluate the effect of water deficits on the growth and biomass distribution in different tissues of lucerne, plant height, leaf dry weight, leaf number and area, root dry weight, taproot length and lateral root number, and stem dry weight were measured at four stages from the seedling to flowering stages under three water regimes: (i) adequate water supply (minimum soil water content $85 \%$ pot capacity (PC)), (ii) moderate water stress (65\% PC), and (iii) severe water stress ( $45 \%$ PC), imposed under a rainout shelter. With limited water supply, plant height, leaf number, leaf area and dry weight, taproot length, and total biomass were reduced, while lateral root numbers increased. The number of smaller leaves and root dry weight increased under moderate water stress, whereas severe water stress reduced them. Leaf, stem, and total dry weight were all reduced by the water deficits, but leaf dry weight was reduced the most and root dry weight the least, so there was a redistribution of biomass towards the roots, increasing the root-shoot ratio. These results help us to understand the response of lucerce to water stress and assist in developing a foundation for the sustainable use of lucerne in semi-arid agricultural systems.
\end{abstract}

Keywords: alfalfa; biomass; lateral root number; leaf growth; plant height; taproot length

\section{Introduction}

Drought stress is one of the most important abiotic stresses on a global scale, causing major crop losses [1]. Adverse growing conditions, especially an increase in aridity, are the main reasons for reductions in the potential yield of major crops [2]. The tolerance of plants to drought stress is a complex phenomenon that involves specific morphological, physiological, biochemical, and metabolic adaptations that affect plant growth, development, and survival [3-6]. Plants respond to water deficits by strategies including drought escape, drought avoidance, and drought tolerance $[7,8]$, but the adjustment of phenology to escape or avoid severe water shortage and the metering of water use to provide sufficient resources for the reproductive phase predominate in grain crops [9]. For perennial pasture species such as lucerne, the ability to use available water to maximize aboveground biomass, and survival of drought episodes, are more important than conserving water for the reproductive phase [10]. Nasreddine et al. [11] reported that the growth patterns of different plant organs are affected 
differently by drought stress. For example, plant morphological components such as leaf area will often be modified to reduce water loss by transpiration [12], and the distribution of assimilates are altered to maximize root exploration of the soil, leading to an increase in the root-shoot dry matter ratio (R/S) [13]. Pasture yield is also influenced by the redistribution of stored assimilates into economically important organs [14].

Lucerne/alfalfa (Medicago sativa L.) is one of the most popular pasture species in semi-arid regions $[14,15]$ and plays a critical role in sustaining agricultural systems by diversifying crop rotations, providing highly nutritious livestock feed, enhancing soil quality through biological nitrogen fixation [16-18], and benefiting soil and water conservation [19]. Lucerne is an extremely adaptable plant that can be grown under a wide range of climatic conditions from the equatorial to polar regions [20,21]. However, water availability is one of the primary factors limiting its distribution, growth, and development. The planted area of lucerne is the largest among forage species in China. It has been grown for at least 150 years on the Loess Plateau of northwestern China [22] where the long-term annual precipitation is $250-400 \mathrm{~mm} \mathrm{[23]} \mathrm{and} \mathrm{where} \mathrm{precipitation} \mathrm{is} \mathrm{the} \mathrm{major} \mathrm{source} \mathrm{of}$ water supply for crops and pastures. M. sativa L. cv. Xinjiangdaye was successfully introduced to the Loess Plateau in 1989, but little research has been undertaken on why it has been such a successful pasture species for the past three decades. There is therefore a need to identify the morphological and physiological features of lucerne that influence its growth and productivity in conditions of water limitation. Although the general effects of drought on growth of lucerne have been studied [24-26], and an expanded root system reported under water-limited conditions [27], further investigation on the growth of lucerne under water-limited conditions at the early growth stage is warranted, as lucerne is reportedly not drought-tolerant during the first 2 to 5 months of its growth [26]. In particular, growth and physiological parameters such as the partitioning of biomass to different tissues/organs need to be clarified and quantified.

The present study was initiated to investigate the effects of drought stress on vegetative growth, leaf features, and biomass distribution over the early growth stages of $M$. sativa Xinjiangdaye, from seedling emergence to flowering, in order to understand the morphological and physiological basis of lucerne establishment, growth, and development under water-limited conditions and the likely limitations to its early growth in semi-arid environments.

\section{Materials and Methods}

\subsection{Materials}

Lucerne (Medicago sativa. L. cv. Xinjiangdaye) seeds were kindly provided by the Key Laboratory of Grassland Ecosystems of the Ministry of Education of China. Plastic pots, $350 \mathrm{~mm}$ in diameter and $400 \mathrm{~mm}$ in height with holes at the base to allow for drainage, were used to grow the plants. Each pot was filled with $9.5 \mathrm{~kg}$ of air-dried sandy-loam topsoil collected from the campus of Gansu Agricultural University with a measured pot capacity (PC) of $25.7 \%$ (determined by watering to complete saturation, allowed to drain for $24 \mathrm{~h}$ before weighing (wet weight), and oven-drying the soil for $24 \mathrm{~h}$ (dry weight), then $\mathrm{PC}=(($ wet weight - dry weight $) /($ dry weight - empty pot weight $)) \times 100)$. The soil in each pot was mixed with $0.5 \mathrm{~kg}$ of livestock manure and $1 \mathrm{~L}$ of nutrient solution $\left(\mathrm{NH}_{4} \mathrm{NO}_{3}: 5.42 \mathrm{~g} / \mathrm{L}, \mathrm{KH}_{2} \mathrm{PO}_{4}\right.$ : $2.33 \mathrm{~g} / \mathrm{L}$ ) was applied before sowing.

\subsection{Methodology}

A total of 48 pots (three water treatments, plants harvested at four growth stages, four replicates) were arranged in a randomized complete block design, with water treatments and harvest stages completely randomized in four replicate blocks. The three water treatments were (i) adequate water supply (WW, minimum soil water content (SWC) $=85 \%$ PC); (ii) moderate water stress (MS, minimum SWC $=65 \%$ PC), and (iii) severe water stress (SS, minimum SWC $=45 \% \mathrm{PC}$ ). The experiment was conducted in 2017 under a rainout shelter $(3 \mathrm{~m}$ long $\times 5 \mathrm{~m}$ wide $\times 2.7 \mathrm{~m}$ high that was open except 
during rain events) in the experimental field of the College of Forestry at Gansu Agricultural University (36 $09^{\prime}$ N, $103^{\circ} 70^{\prime}$ E, altitude 1620 m), Lanzhou, Gansu Province, China. Before sowing, each pot was watered until water drained from the holes at the base of the pots. Twenty seeds were sown in each pot on 1 April 2017. A preliminary experiment showed that from 7 days after sowing (DAS), no further lucerne seeds were likely to emerge, so on 8 April, plants were thinned to three per pot and the three water treatments imposed. In all treatments, the SWC reached the predetermined levels of $85 \%, 65 \%$, and $45 \%$ PC within 48 h. Each pot was weighed at $17.30 \mathrm{~h}$ Beijing Standard Time (BST) each day and re-watered to the three predetermined levels of $85 \%, 65 \%$, and 45\% PC. After 14 days (22 April-the seedling stage at which the plants had two leaves), 28 days (6 May-branching stage at which the internodes were elongated with branches on the main stem), 42 days (20 May-squaring when many buds developed), and 56 days (3 June-flowering when many flowers had opened), the three plants per pot in each replicate were harvested at soil level and the mean values of the three plants were used for further analysis. Plant height and leaf area were measured with a ruler and leaf area meter (Li-3100, LiCor, Lincoln, NE, USA), respectively, and leaf number was counted. The roots were washed with water to remove the soil, wiped dry with a paper towel, the length of the taproot was measured, and the lateral root number was counted. The harvested plants were separated into leaves, stems, and roots, and the dry weight of each was obtained after oven-drying at $65{ }^{\circ} \mathrm{C}$ for $48 \mathrm{~h}$. The growth rate (GR) and root-to-shoot dry weight ratio (R/S) were calculated.

$$
\mathrm{GR}=\left(\text { dry weight at } \mathrm{t}_{2}-\text { dry weight at } \mathrm{t}_{1}\right) /\left(\mathrm{t}_{2}-\mathrm{t}_{1}\right)
$$

in which $t_{1}$ and $t_{2}$ are the days to the different growth stages.

$$
\mathrm{R} / \mathrm{S}=\text { root dry weight/(stem dry weight + leaf dry weight) }
$$

\subsection{Statistical Analyses}

The general analysis of variance (ANOVA) in SPSS 12.0 software (SPSS, Chicago, IL, USA) was used to test for significance of all measured variables. Before each ANOVA, the homogeneity of the variances was tested and the data met the normal and equal variance assumptions of ANOVA without transformation. Comparisons of means among organs and between treatments were carried out via Tukey's test at $p<0.05$.

\section{Results}

\subsection{Effect of Water Treatments on Plant Height and Leaf Growth}

In the water-sufficient treatment (85\% PC), the height of the plants at the seedling stage was $157 \pm 5 \mathrm{~mm}$, and by flowering this had reached $541 \pm 22 \mathrm{~mm}$ (Figure 1A). Height growth was not linear over this period, but plants grew at $7.8 \pm 2.1 \mathrm{~mm} \mathrm{day}^{-1}$ between seedling and branching, $6.9 \pm 0.9 \mathrm{~mm} \mathrm{day}^{-1}$ between branching and squaring, and $5.9 \pm 0.5 \mathrm{~mm}$ day $^{-1}$ between squaring $^{-1}$ and flowering. In the moderate water stress treatment (65\% PC), height was reduced at all stages compared with the water-sufficient treatment (Figure 1A) due to a slowing of the rate of height growth between the seedling and squaring stages. In the severe stress treatment (45\% PC), the height of the plants was reduced further at all stages (Figure 1A); the rate of growth was approximately linear at $4.5 \pm 0.3 \mathrm{~mm} \mathrm{day}^{-1}$ from the seedling to flowering stages. 


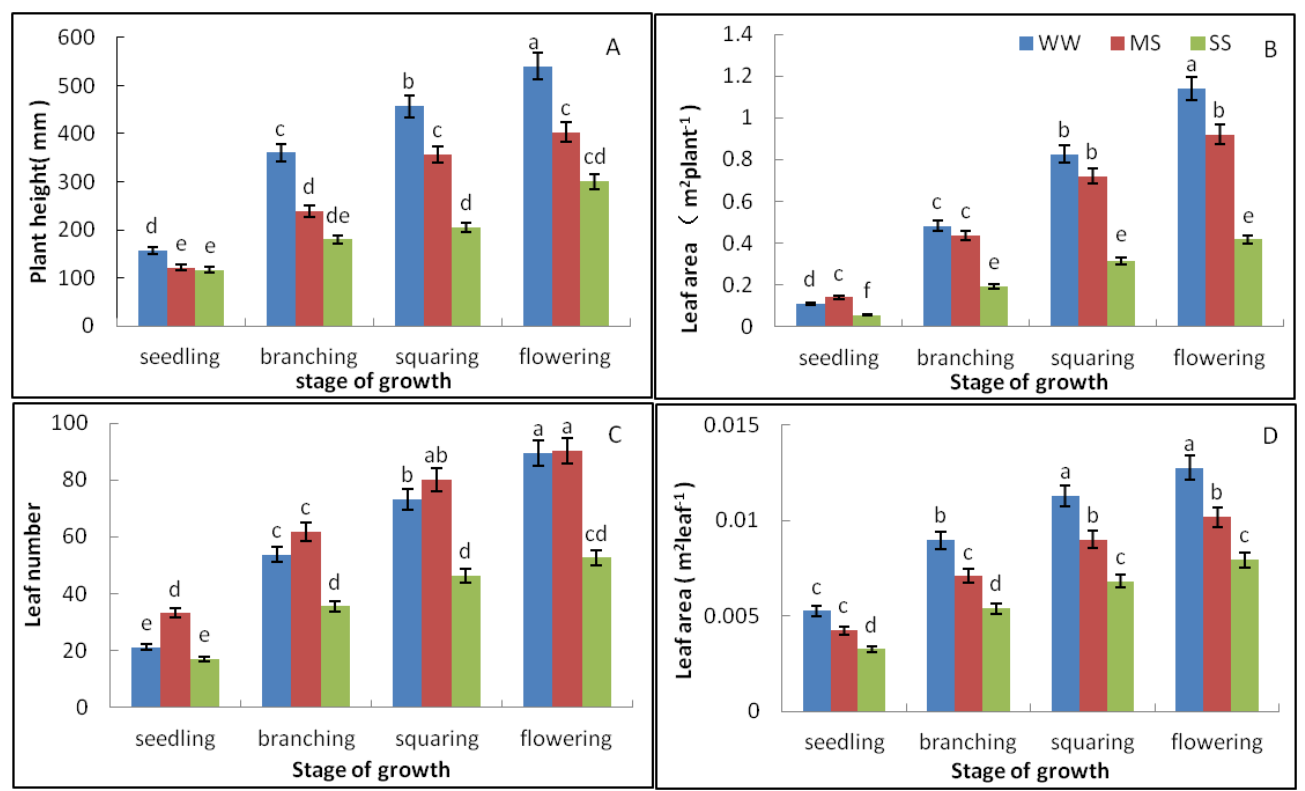

Figure 1. Effect of watering treatments (WW: water-sufficient (85\% pot capacity (PC)), MS: moderate water stress (65\% PC), and SS: severe water stress (45\% PC)) on (A) plant height, (B) leaf area per plant, (C) leaf number per plant, and (D) leaf area per leaf at the four growth stages: seedling, branching, squaring, and flowering. The bars are \pm one standard error of the mean $(n=4)$. Different lower case letters represent significant differences at $p<0.05$ according to Tukey's multiple range test.

In the water-sufficient treatment (85\% PC), the leaf area plant $^{-1}$ increased approximately linearly from $0.11 \pm 0.03 \mathrm{~m}^{2}$ plant $^{-1}$ at the seedling stage to $1.14 \pm 0.37 \mathrm{~m}^{2}$ plant $^{-1}$ at flowering (Figure 1B). In the moderate stress treatment (65\% PC), the leaf area was reduced by about $20 \%$ at all stages, but this was only statistically significant at the flowering stage (Figure $1 \mathrm{~B}, p<0.05$ ). However, the leaf area was significantly reduced in the severe water stress treatment ( $45 \%$ PC) by about $60 \%$ at all stages (Figure $1 \mathrm{~B}, p<0.05$ ). The reduction in area was the result of a reduction in both the number of leaves (Figure 1C) and area per leaf (Figure 1D). The moderate stress (65\% PC) only had a significant effect on leaf number at the seedling stage of growth $(p<0.05)$, but the severe stress treatment $(45 \%$ PC) reduced the number of leaves by about a third at all stages of development (Figure 1C), while the area per leaf was reduced by the moderate stress (Figure 1D). Throughout the period of development, the leaf size was reduced by about $20 \%$ by the moderate stress $(65 \% \mathrm{PC})$, and by about $35 \%$ by the severe stress treatment ( $45 \%$ PC) (Figure 1D).

\subsection{Effect of Water Treatments on Taproot Length and Lateral Root Number}

By the seedling stage, the length of the taproot in the water-sufficient treatment (85\% PC) was 183 $\pm 15 \mathrm{~mm}$, and this increased to $387 \pm 23 \mathrm{~mm}$ by branching and $628 \pm 35 \mathrm{~mm}$ by flowering (Figure 2A); i.e., the root length growth was $16 \%$ greater than the plant height growth over the same period (Figure 1A). The rate of length growth was fastest between the seedling and branching stages at $14.5 \mathrm{~mm} \mathrm{day}^{-1}$, and decreased to about $60 \%$ of this rate between branching and flowering. Taproot length was reduced by both water stress treatments (Figure 2A); at the seedling and branching stages, the taproot was not significantly shorter in the moderate stress treatment $(65 \% \mathrm{PC}, p<0.05)$, but at flowering it was significantly reduced $(p<0.05)$ by $19 \%$, compared with the water-sufficient lucerne (Figure 2A). The severe stress treatment $(45 \%$ PC) reduced the rate of taproot growth by $50 \%$ in the period between the seedling and branching stages and to a more severe degree thereafter, so that by flowering the taproot was $325 \pm 12 \mathrm{~mm}$ long in the severe stress treatment, $478 \pm 25 \mathrm{~mm}$ long in the moderate stress treatment, and $628 \pm 35 \mathrm{~mm}$ long in the water-sufficient plants (Figure 2A). 


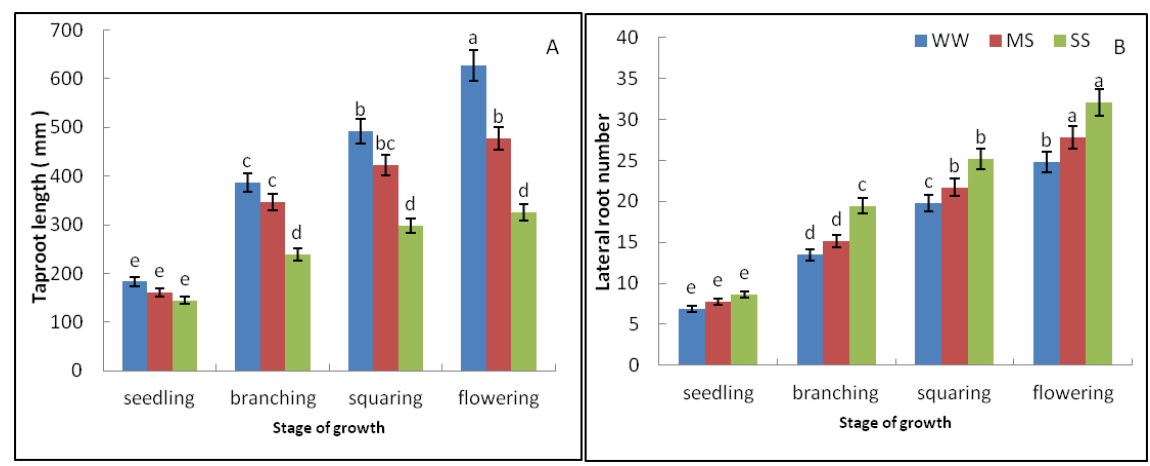

Figure 2. Effect of watering treatment (WW: water-sufficient (85\% PC), MS: moderate water stress (65\% PC), and SS: severe water stress (45\% PC)) on (A) taproot length and (B) lateral root number per plant at four growth stages: seedling, branching, squaring, and flowering. The bars are \pm one standard error of the mean $(n=4)$. Different lowercase letters represent significant differences at $p<0.05$ according to Tukey's multiple range test.

Water stress increased the number of lateral roots in the lucerne (Figure 2B). The lateral root number in the water-sufficient treatment increased approximately linearly from 7 plant $^{-1}$ at the seeding stage to 25 plant $^{-1}$ at flowering. Moderate and severe stress increased the number of lateral roots by $12-18 \%$ and by $25-29 \%$, respectively, over the water-sufficient treatment. While the numbers were always higher in the severe than the moderate stress at all stages of development, the differences were only significant $(p<0.05)$ at the branching stage. (Figure $2 \mathrm{~B})$.

\subsection{Effect of Water Treatments on Leaf, Stem, and Root Dry Weight}

The total dry weight at the seedling stage in all three water treatments was $0.14 \pm 0.08 \mathrm{~g} \mathrm{plant}^{-1}$, and increased in the water-sufficient plants to $0.51 \pm 0.11 \mathrm{~g} \mathrm{plant}^{-1}$ by flowering (Figure 3A). With reduced water supply, the total dry weight accumulation decreased in both the moderate water stress and severe water stress treatments, so that by flowering the total dry weight in moderate water stress (65\% PC) and severe water stress (45\% PC) was $93 \%$ and $67 \%$ of that in the water-sufficient treatment, respectively (Figure 3A). The reduction in total dry weight in the moderate stress treatment was always less than $10 \%$ and was not statistically significant $(p>0.05)$ between the seedling and squaring stages.

Both the leaf and stem dry weights were reduced by the water stress treatments (Figure 3B,C). In the water-sufficient treatment $(85 \% \mathrm{PC})$, the leaf dry weight $\left(0.05 \pm 0.01\right.$ to $\left.0.20 \pm 0.06 \mathrm{~g} \mathrm{plant}^{-1}\right)$ was similar to the stem dry weight $\left(0.05 \pm 0.01\right.$ to $\left.0.18 \pm 0.03 \mathrm{~g} \mathrm{plant}^{-1}\right)$, but the reduction in dry weight was greater in the leaf than in the stem at all developmental stages, particularly at squaring and flowering (Figure 3B,C). For example, at flowering, the reduction in leaf dry weight was $26 \%$ and $56 \%$ in the moderate and severe stress treatments, respectively, while in the stems the reduction in dry weight was $6 \%$ and $31 \%$, respectively.

In the moderate water stress treatment, the root dry weight was always higher than in the water-sufficient treatment, significantly so at squaring and flowering (Figure $3 \mathrm{D}, p<0.05$ ). By contrast, the root dry weight in the severe stress treatment was significantly lower $(p<0.05)$ than in the water-sufficient and moderately stressed treatments at branching, squaring, and flowering (Figure 3D). At flowering, the root dry weight was $16 \%$ higher in the moderate stress treatment and $10 \%$ lower in the severe stress treatment than in the water-sufficient treatment. 


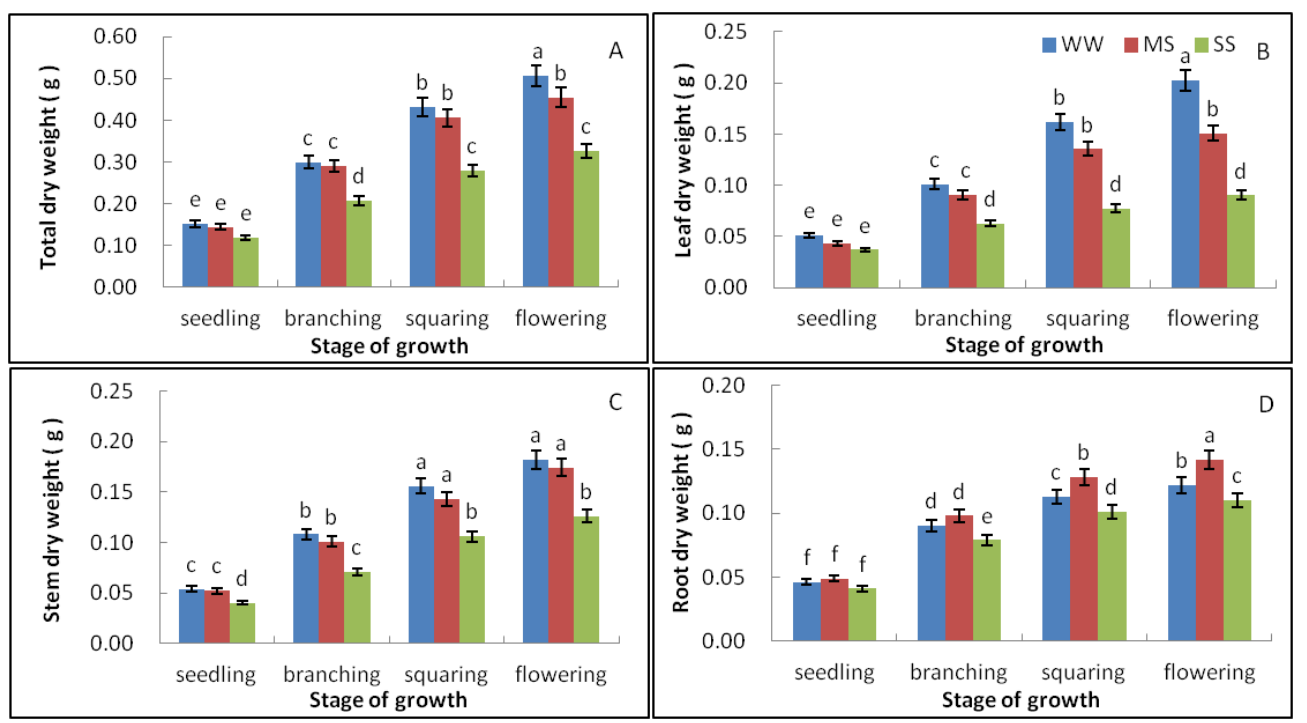

Figure 3. Effect of watering treatment (WW: water-sufficient ( $85 \%$ PC), MS: moderate water stress (65\% PC), and SS: severe water stress (45\% PC)) on (A) total dry weight per plant, (B) leaf dry weight per plant, (C) stem dry weight per plant, and (D) root dry weight per plant at four growth stages: seedling, branching, squaring, and flowering. The bars are \pm one standard error of the mean $(n=4)$. Different lowercase letters represent significant differences at $p<0.05$ according to Tukey's multiple range test.

Dry matter was distributed to the different organs at different rates depending on water availability (Figure 4). At the seedling stage, the distribution of dry matter was similar in the leaves, stems, and roots in all the water treatments, and the R/S ratio was 0.47 (Table 1 ). In the water-sufficient treatment, the $R / S$ ratio was similar at branching to that at seeding, but then decreased at the squaring stage and decreased further at the flowering stage as a greater proportion of the assimilates was distributed to the leaves (Figure 4). With increasing water stress, the total dry matter of the plants decreased and a greater proportion of this dry matter was distributed to the roots and less to the leaves (Figure 4)

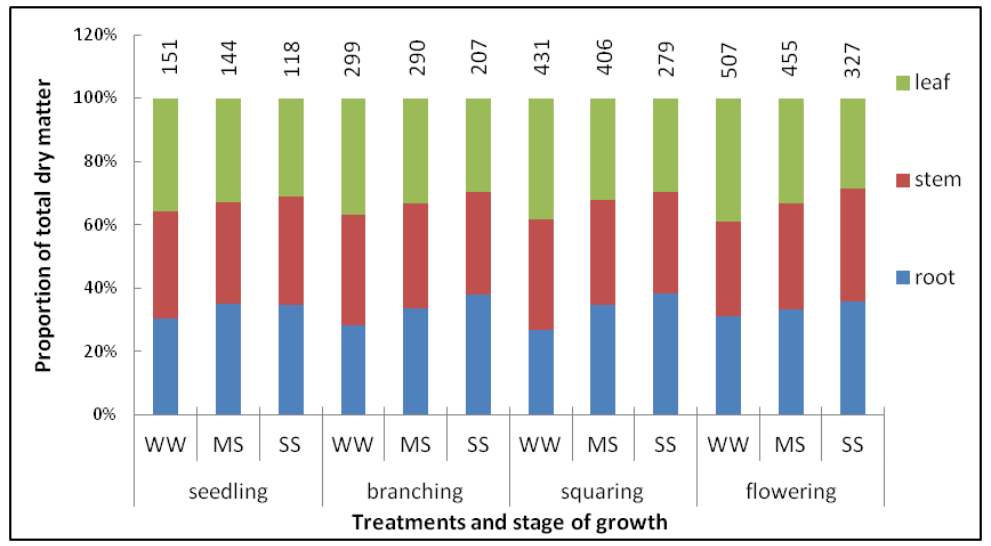

Figure 4. Effect of watering treatment (WW: water-sufficient ( $85 \%$ PC), MS: moderate water stress (65\% PC), and SS: severe water stress (45\% PC)) on the proportion of the total dry matter in the leaves, stems, and roots at the different growth stages: seedling, branching, squaring, and flowering. The values above the bars give the total dry matter (mg/plant) shown in Figure 3A. 
Table 1. Effect of three watering treatments (WW: water-sufficient (85\% PC), MS: moderate water stress (65\% PC), and SS: severe water stress ( $45 \%$ PC)) on the growth rate and root/shoot ratio of lucerne at different growth stages: seedling, branching, squaring, and flowering. The mean growth rates and root/shoot ratios for the period from the beginning of the water treatments to flowering are also given. The values are means \pm standard error of the mean $(n=4)$.

\begin{tabular}{cccc}
\hline & & Growth Rate $\left(\mathbf{m g}\right.$ day $\left.^{-\mathbf{1}}\right)$ & Root/Shoot Ratio \\
\hline \multirow{4}{*}{ WW } & Seedling & $10.8 \pm 6.4$ & 0.47 \\
& Branching & $10.6 \pm 7.5$ & 0.45 \\
& Squaring & $9.4 \pm 1.3$ & 0.32 \\
& Flowering & $5.9 \pm 1.0$ & 0.26 \\
& Mean & $9.2 \pm 1.5$ & 0.38 \\
MS & Seedling & $10.3 \pm 6.9$ & 0.48 \\
& Branching & $10.4 \pm 7.7$ & 0.50 \\
& Squaring & $8.3 \pm 1.2$ & 0.42 \\
& Flowering & $4.3 \pm 1.0$ & 0.42 \\
& Mean & $8.3 \pm 2.1$ & 0.46 \\
& Seedling & $8.4 \pm 2.6$ & 0.51 \\
& Branching & $6.3 \pm 1.8$ & 0.55 \\
& Squaring & $5.6 \pm 0.9$ & 0.73 \\
& Flowering & $3.8 \pm 0.8$ & 0.38 \\
& Mean & $6.0 \pm 2.5$ & 0.54 \\
\hline
\end{tabular}

\section{Discussion}

Water deficits are well known to reduce the growth of most crops and pastures $[3,8,10,25,26]$. We chose to study the effect of water shortage on the early growth of Lucerne, as it has been stated that "seedling alfalfa (alfalfa during its first 2 to 5 months of growth) is not as drought tolerant as is established alfalfa (lucerne), so moisture stress at this time should be avoided. If soil moisture is inadequate during the establishment phase, excessive plant mortality and stand loss can occur" [26]. However, in arid and semi-arid areas in which lucerne is grown, drought stress cannot always be avoided during establishment and early vegetative growth. In this study, we showed that water deficits in the vegetative stage reduced the production of aboveground forage, largely as a result of a reduction in leaf biomass and leaf area due to the production of smaller leaves, particularly under severe stress $(45 \% \mathrm{PC})$. The water stress treatments also reduced the length of the taproot, but increased lateral root development and, in the moderate stress (65\% PC) treatment, increased the root biomass. The increase in dry weight of the roots in the moderate and severe water stress treatments with development was proportionally greater than in the leaves, resulting in the R/S ratio increasing with increasing water deficit.

The development of leaf area is important in determining the growth rate and water use of lucerne, and it increased linearly in the water-sufficient plants. The lucerne plants were able to maintain their leaf area and the number of leaves until flowering at moderate stress (65\% PC), but severe stress $(45 \%$ PC) significantly reduced the leaf area throughout growth from the seedling to the flowering stages as a result of fewer ( $42 \%$ fewer by flowering) and smaller ( $40 \%$ smaller at flowering) leaves compared with leaves in the water-sufficient plants. Maintenance of leaf area at moderate stress with an increased number of smaller leaves will maintain photosynthesis and biomass accumulation, and hence forage amount and quality, but at the expense of greater water use. We did not measure water use or photosynthesis in this study, but the rate of total biomass accumulation was similar in the water-sufficient lucerne and moderately stressed lucerne until flowering, suggesting that maintenance of leaf area was an adaptation to limited water in lucerne. By contrast, leaf area was markedly reduced by the severe water stress treatment, indicating that the reduction in leaf area was an adaptation to the very limited water availability. These morphological responses are associated with plant drought adaptation strategies, and plasticity of leaf number and size is an important component of drought adaptation [28]. 
The changes in total dry weight from the 5-day-old seedlings when the treatments were imposed to flowering showed that the overall growth rate decreased from $9.2 \mathrm{mg} \mathrm{day}^{-1}$ in the water-sufficient lucerne plants to $8.3 \mathrm{mg} \mathrm{day}^{-1}$ (91\% of the water-sufficient treatment) in those subjected to moderate water stress, and to $6.0 \mathrm{mg} \mathrm{day}^{-1}$ (66\% of the water-sufficient treatment) in those in the severe stress treatment. In all three water treatments, the fastest growth occurred at the seedling and branching stages, the slowest at the flowering stage (Table 1). The more severe the water stress, the greater the proportion of seedling and branching stage growth in terms of the entire growth from the seedling to flowering stages (Table 1$)$. The $R / S$ ratio remained relatively constant $(0.42$ to 0.50$)$ in the moderate stress treatment (Table 1). However, in the severe stress treatment, the assimilate distribution to the leaves was severely reduced by the water stress while assimilate distribution to the roots was similar to that in the water-sufficient lucerne, so the R/S ratio increased to 0.55 at branching, reached 0.73 at squaring and then decreased again to 0.38 at flowering (Table 1), primarily as a result of a smaller proportion of dry matter being distributed to the leaves (Figure 4). Not only was root dry weight increased in the moderate stress treatment, but also the number of lateral roots, enabling greater water uptake from the drying soil. This confirmed a previous observation that roots of lucerne seedlings are more resilient to water deficits than the leaves or stems, and not just at the seedling stage [29], but also throughout the vegetative stage to flowering. In this way, plants can reduce the consumption of water by minimizing the evaporative area and water use, a drought-avoidance strategy [30], while fully exploring the soil volume for water. Similar results have been reported [31] in which moderate and severe drought stress reduced the growth of shoots rather than roots, compared to the water-sufficient treatments. Our results were in accordance with these studies: leaf area and taproot length decreased in response to water stress, which can be explained by cessation of cell division and elongation [32]. Rasekh et al. indicated that water deficit conditions during vegetative growth influence cell division and enlargement, which consequently suppress plant height, leaf growth, and its development [33]. However, the reduction in taproot growth may have been the result of the restricted root growth in pots, particularly as a result of frequent watering from the top of the pot [34]

The different water stress levels applied in our experiment induced different growth responses in lucerne, indicating that the severity of water stress and the development of water stress must be taken into consideration when developing a management strategy for lucerne. The observation that taproot length was reduced by the reduction in water availability suggests that if irrigation is available, application of water to prevent a reduction in taproot growth would be beneficial, as anecdotal evidence suggests that the root system should be 1 to $1.5 \mathrm{~m}$ depth in the soil before the onset of severe stress [26]. If irrigation is not available, withholding grazing or harvesting in the late vegetative stage should be avoided to maintain biomass and reserves for regrowth when the water shortage is relieved.

Author Contributions: Y.-Z.L. and G.L. conceived and designed the experiments; Y.-Z.L. performed the experiments; Y.-Z.L., G.L. and N.C.T. analyzed the data and wrote the manuscript; Y.-Z.L., H.L., G.Y. and N.C.T. assisted with writing, reviewing and editing the paper. All authors have read and agreed to the published version of the manuscript.

Acknowledgments: Financial support for this research came from Gansu Agricultural University discipline construction special foundation (GAU-XKJS-2018-111), the National Natural Science Foundation of China (Project 31560238), the Provincial Natural Science Foundation of Gansu (Projects 17JR5RA145). Y.-Z.L. thanks the Gansu Agricultural University for study leave and The University of Western Australia for supporting a 1-year appointment as Visiting Professor.

Conflicts of Interest: The authors declare no conflict of interest.

\section{References}

1. Turner, N.C.; Molyneux, N.; Yang, S.; Xiong, Y.C.; Siddique, K.H.M. Climate change in south-west Australia and north-west China: Challenges and opportunities for crop production. Crop Pasture Sci. 2011, 62, 445-456. [CrossRef] 
2. Parry, M.L.; Rosenzweig, C.; Iglesias, A.; Livermore, M.; Fischer, G. Effects of climate change on global food production under SRES emissions and socio-economic scenarios. Glob. Environ. Chang. 2004, 14, 53-67. [CrossRef]

3. Farooq, M.; Wahid, A.; Kobayashi, N.; Fujita, D.; Basra, S.M.A. Plant drought stress: Effects, mechanisms and management. Agron. Sustain. Dev. 2004, 29, 153-188.

4. Wang, X.; Marija, V.; Liu, F.; Susanne, J.; Dong, J.; Bernd, W. Drought priming at vegetative growth stages improves tolerance to drought and heat stresses occurring during grain filling in spring wheat. Plant Growth Regul. 2015, 75, 677-687. [CrossRef]

5. Easwar, D.R.; Chaitanya, K.V. Photosynthesis and antioxidative defense mechanisms in deciphering drought stress tolerance of crop plants. Biol. Plant. 2016, 60, 201-218. [CrossRef]

6. Joshi, R.; Wani, S.H.; Singh, B.; Bohra, A.; Dar, Z.A.; Lone, A.A.; Singla, S.L. Transcription factors and plants response to drought stress: Current understanding and future directions. Front. Plant Sci. 2016, 7, 1029. [CrossRef]

7. Chimenti, C.A.; Hall, A.J. Responses to water stress of apoplastic water fraction and of elasticity in sunflower (Helianthus annuus L.) genotypes capacity for osmotic adjustment. Plant Soil 1994, 166, 101-107. [CrossRef]

8. Turner, N.C. Crop water deficits: A decade of progress. Adv. Agron. 1986, 39, 1-51. [CrossRef]

9. Gabriel, M.M.; Jesu's, J.C.; Sara, P.; Carmen, P.R.; Rube'n, M.; Jorge, A.; Melchor, M. Summer-drought constrains the phenology and growth of two coexisting Mediterranean oaks with contrasting leaf habit: Implications for their persistence and reproduction. Trees 2009, 23, 787-799. [CrossRef]

10. Turner, N.C.; Begg, J.E. Responses of pasture plants to water deficits. In Plant Relations in Pastures; Wilson, J.R., Ed.; CSIRO: Melbourne, Australia, 1978; pp. 50-66.

11. Nasreddine, Y.; Ncib, S.; Amari, R.; Chedly, A. Growth, potosynthesis and water relations as affected by different drought regimes and subsequent recovery in Medicago laciniata (L.) populations. Plant Biol. 2016, 59, 33-43. [CrossRef]

12. David, L.; Warren, K.C.; Richard, E.V. Adaptation of potato to water shortage: Irrigation management and enhancement of tolerance to drought and salinity. Potato Res. 2013, 90, 186-206. [CrossRef]

13. French, R.J.; Turner, N.C. Water deficits change dry matter partitioning and seed yield in narrow-leafed lupins (Lupinus angustifolius L.). Aust. J. Agric. Res. 1991, 42, 471-484. [CrossRef]

14. Lalith, D.S.; Megan, H.R.; Michael, R.; Hans, L. Above- and below-ground interactions of grass and pasture legume species when grown together under drought and low phosphorus availability. Plant Soil 2011, 348, 281-297. [CrossRef]

15. Jiang, H.M.; Jiang, J.P.; Jia, Y.; Li, F.M.; Xu, J.Z. Soil carbon pool and effects of soil fertility in seeded alfalfa fields on the semi-arid Loess Plateau in China. Soil Biol. Biochem. 2006, 38, 2350-2358. [CrossRef]

16. Peoples, M.B.; Bowman, A.M.; Gault, R.R.; Herridge, D.F.; McCallum, M.H.; McCormick, K.M.; Norton, R.M.; Rochester, I.J.; Scammell, G.J.; Schwenke, G.D. Factors regulating the contributions of fixed nitrogen by pasture and crop legumes to different farming systems of eastern Australia. Plant Soil 2001, 228, $29-41$. [CrossRef]

17. Norton, M.R.; Malinowski, D.P.; Volaire, F. Plant drought survival under climate change and strategies to improve perennial grasses. A review. Agron. Sustain. Dev. 2016, 36, 29-44. [CrossRef]

18. Carlsson, G.; Danell, K.H. Nitrogen fixation in perennial forage legumes in the field. Plant Soil 2003, 253, 353-372. [CrossRef]

19. Jia, Y.H.; Shao, M.A. Temporal stability of soil water storage under four types of revegetation on the northern Loess Plateau of China. Agric. Water Manag. 2013, 117, 33-42. [CrossRef]

20. Sumberg, J.E.; Murphy, R.P.; Lowe, C.C. Selection for fiber and protein concentration in a diverse alfalfa population. Crop Sci. 1983, 23, 11-14. [CrossRef]

21. Fan, J.W.; Du, Y.L.; Turner, N.C.; Wang, B.R.; Fang, Y.; Xi, Y.; Guo, X.R.; Li, F.M. Changes in root morphology and physiology to limited phosphorus and moisture in a locally-selected cultivar and an introduced cultivar of Medicago sativa L. growing in alkaline soil. Plant Soil 2015, 392, 215-226. [CrossRef]

22. Jia, Y.; Li, F.M.; Wang, X.L. Soil quality responses to alfalfa watered with a field micro-catchment technique in the Loess Plateau of China. Field Crop. Res. 2006, 95, 64-74. [CrossRef]

23. He, S.; Liu, G.; Yang, H. Water use efficiency by alfalfa: Mechanisms involving anti-oxidation and osmotic adjustment under drought. Russ. J. Plant Physiol. 2012, 59, 348-355. [CrossRef] 
24. Richard, E.S.; Hamish, E.B.; Edmar, I.T.; Derrick, J.M. Soil water extraction patterns of lucerne grown on stony soils. Plant Soil 2017, 414, 95-112. [CrossRef]

25. Bell, L.W.; Williams, A.H.; Ryan, M.H.; Ewing, M.A. Water relations and adaptations to increasing water deficit in three perennial legumes, Medicago sativa, Dorycnium hirsutum and Dorycnium rectum. Plant Soil 2007, 290, 231-243. [CrossRef]

26. Orloff, S.; Putnam, D.; Bali, K. Drought Strategies for Alfalfa; University of California Agriculture and Natural Resources Publication: Richmond, CA, USA, 2015.

27. Pang, J.Y.; Yang, J.Y.; Ward, P.; Siddique, K.H.M.; Lambers, H.; Tibbett, M.; Ryan, M. Contrasting responses to drought stress in herbaceous perennial legumes. Plant Soil 2011, 348, 299-314. [CrossRef]

28. Gernot, B.; Alireza, N.; Hans, P.K. Management of crop water under drought: A review. Agron. Sustain. Dev. 2015, 35, 401-442. [CrossRef]

29. Luo, Y.Z.; Liu, H.; Yan, G.J.; Li, G.; Turner, N.C. Roots of lucerne seedlings are more resilient to a water deficit than leaves or stems. Agronomy 2019, 9, 123. [CrossRef]

30. Xu, W.; Cui, K.H.; Xu, A.H.; Nie, L.X.; Huang, J.L.; Peng, S.B. Drought stress condition increases root to shoot ratio via alteration of carbohydrate partitioning and enzymatic activity in rice seedlings. Acta Physiol. Plant. 2015, 37, 9. [CrossRef]

31. Khonghintaisong, J.; Songsri, P.; Toomsan, B.; Jongrungklang, N. Rooting and physiological trait responses to early drought stress of sugarcane cultivars. Sugar Technol. 2018, 20, 396-406. [CrossRef]

32. Brown, H.E.; Moot, D.J.; Fletcher, A.L.; Jamieson, P.D. A framework for quantifying water extraction and water stress responses of pernnial lucerne. Crop Pasture Sci. 2009, 60, 785-794. [CrossRef]

33. Amiri, R.; Nikbakht, A.; Rahimmalek, M.; Hosseini, H. Variation in the essential oil composition, antioxidant capacity, and physiological characteristics of Pelargonium graveolens L. inoculated with two species of mycorrhizal fungi under water deficit conditions. J. Plant Growth Regul. 2017, 36, 502-515. [CrossRef]

34. Turner, N.C. Imposing and maintaining soil water deficits in drought studies in pots. Plant Soil 2019, 439, 45-55. [CrossRef]

(C) 2020 by the authors. Licensee MDPI, Basel, Switzerland. This article is an open access article distributed under the terms and conditions of the Creative Commons Attribution (CC BY) license (http://creativecommons.org/licenses/by/4.0/). 